\title{
Family history of premature death from ischaemic heart disease is associated with an increased risk of delivering a low birth weight baby
}

\author{
J P Pell, G C S Smith, A Dominiczak, S M Cobbe, R Dobbie, A D McMahon, I Ford
}

Heart 2003;89:1249-1250

\begin{abstract}
t is well recognised that low birth weight babies are at increased risk of vascular and metabolic diseases in later life. ${ }^{12}$ Barker and colleagues postulated that this was the result of fetal adaptation to inadequate intrauterine nutrition. ${ }^{1}$ If true, dietary supplementation of women should be considered as a potential public health intervention to reduce the burden of ischaemic heart disease in future generations. However, recent studies have demonstrated that mothers of low birth weight babies were themselves at increased risk of later ischaemic heart disease. ${ }^{3}$ This finding is difficult to explain by the Barker hypothesis and points to a possible common genetic predisposition to both ischaemic heart disease and pregnancy complications. Many genetic variants have been shown to be associated with an increased risk of ischaemic heart disease and many more are likely to exist which remain to be discovered. In the present study we used family history of premature death from ischaemic heart disease as a proxy measure of overall genetic predisposition, and predicted that women with a positive family history would be at increased risk of a low birth weight baby.
\end{abstract}

\section{METHODOLOGY}

The West of Scotland coronary prevention study (WOSCOPS) screened over 120000 individuals for cardiovascular risk factors between 1989 and 1991. Although women were not recruited into the trial, screening interview data were collected on 15771 women. The WOSCOPS data on these women were linked retrospectively to a Scotland-wide maternity register (Scottish Morbidity Record 2 (SMR2)) which commenced in 1969, to obtain data on their live singleton deliveries. Women were excluded from the study if they had not had a singleton pregnancy since 1969. In those women who had had more than one singleton delivery only data from the first were used. The SMR2 database provided information on birth weight and gestational age at delivery, and SMR2 and WOSCOPS provided data on potential confounding factors.

\section{RESULTS}

Of the 15771 women screened, 3320 had had a live singleton delivery since 1969 and 3311 also had complete data on birth weight. Of these, $190(5.7 \%)$ delivered a low birth weight $(<2.5 \mathrm{~kg})$ infant and $214(6.5 \%)$ had a preterm delivery $(<37$ weeks) (table 1). Of the 3310 women with recorded information on family history, 1040 (31.4\%) reported premature death from ischaemic heart disease in a first degree relative (males $<55$ years, female $<60$ years).

Sixty eight $(6.5 \%)$ of the 1040 women who reported a family history delivered low birth weight infants, compared with $122(5.4 \%)$ of the 2270 women with no family history (odds ratio (OR) 1.23, 95\% confidence interval (CI) 0.90 to 1.69 ; $p=0.18)$. Low birth weight was entered as the dependent variable in a binary logistic regression model. Multivariate logistic regression analysis was performed to adjust for the potential confounding effects of cigarette and alcohol consumption, body mass index, socioeconomic status, maternal

\begin{tabular}{|c|c|c|c|}
\hline & & n (\%) & Mean (SD) \\
\hline \multicolumn{4}{|l|}{ Demographic } \\
\hline \multirow[t]{2}{*}{ Maternal age } & & & $29(6)$ \\
\hline & Missing & 4 & \\
\hline \multirow{6}{*}{ Deprivation category } & 1 & $278(8)$ & \\
\hline & 2 & 580 (18) & \\
\hline & 3 & $532(16)$ & \\
\hline & 4 & $927(28)$ & \\
\hline & 5 & $983(30)$ & \\
\hline & Missing & 11 & \\
\hline \multicolumn{4}{|l|}{ CHD risk factors } \\
\hline \multirow[t]{4}{*}{ Smoking status } & Non & $1801(54)$ & \\
\hline & Current & 548 (17) & \\
\hline & Ex & $962(29)$ & \\
\hline & Missing & 0 & \\
\hline \multirow{3}{*}{ Alcohol consumption } & No & $1302(40)$ & \\
\hline & Yes & $1954(60)$ & \\
\hline & Missing & 55 & \\
\hline \multirow[t]{3}{*}{ Diabetes mellitus } & No & 3289 (99) & \\
\hline & Yes & $22(1)$ & \\
\hline & Missing & 0 & \\
\hline \multirow[t]{2}{*}{ Body mass index $\left(\mathrm{kg} / \mathrm{m}^{2}\right)$} & & & $25(5)$ \\
\hline & Missing & 2 & \\
\hline \multicolumn{4}{|l|}{ Pregnancy outcomes } \\
\hline \multirow[t]{3}{*}{ Infant sex } & Male & $1606(49)$ & \\
\hline & Female & $1704(51)$ & \\
\hline & Missing & 1 & \\
\hline \multirow[t]{3}{*}{ Low birth weight } & No & 3121 (94) & \\
\hline & Yes & $190(6)$ & \\
\hline & Missing & 0 & \\
\hline \multirow[t]{3}{*}{ Preterm delivery } & No & 3047 (93) & \\
\hline & Yes & $214(7)$ & \\
\hline & Missing & 50 & \\
\hline \multirow[t]{3}{*}{ Parous } & No & $1755(53)$ & \\
\hline & Yes & $1556(47)$ & \\
\hline & Missing & 0 & \\
\hline \multirow{3}{*}{ Pre-eclampsia } & No & $2993(90)$ & \\
\hline & Yes & $318(10)$ & \\
\hline & Missing & 0 & \\
\hline \multirow[t]{3}{*}{ Family history of CHD } & No & 2270 (69) & \\
\hline & Yes & $1040(31)$ & \\
\hline & Missing & & \\
\hline
\end{tabular}

$\mathrm{CHD}$, coronary heart disease.

age, parity, infant's sex, pre-eclampsia, and diabetes mellitus. Family history of premature ischaemic heart disease was independently associated with an increased risk of a low birth weight baby (adjusted OR 1.37, 95\% CI 0.99 to 1.89; $\mathrm{p}=0.05$ ).

The analyses were repeated using preterm delivery and lowest gestation, sex specific birth weight quintile as separate binary outcomes. The association with family history was stronger for preterm delivery (adjusted OR 1.31, 95\% CI 0.97 to $1.77 ; \mathrm{p}=0.08$ ) than lowest birth weight quintile (adjusted OR $1.16,95 \%$ CI 0.94 to $1.43 ; \mathrm{p}=0.16$ ). 


\section{DISCUSSION}

This is the first study, to our knowledge, that demonstrates an association between family history of ischaemic heart disease and an increased risk of pregnancy complications. We previously demonstrated that factors associated with low birth weight, such as poor fetal growth, preterm birth, and preeclampsia, were independently predictive of subsequent maternal ischaemic heart disease. ${ }^{3}$ We hypothesised that this reflected common genetic determinants of both ischaemic heart disease and low birth weight risk. This hypothesis predicts that women with a family history of ischaemic heart disease will be at increased risk of a low birth weight baby. The current data provide supportive evidence for our hypothesis.

Lifestyle risk factors may also be correlated between parents and offspring and some, such as cigarette smoking, predispose to both ischaemic heart disease and delivery of a low birth weight baby. However, the association between family history of ischaemic heart disease and risk of a low birth weight baby was strengthened by adjusting for cigarette and alcohol consumption, body mass index, and socioeconomic status. While we cannot exclude an unmeasured lifestyle or environmental confounder, the current data are consistent with the genetic hypothesis. Because of the relatively small number of women in our cohort, the association was of borderline statistical significance. The current analysis should be replicated in larger studies in which data are available on both family history and pregnancy outcome.

\section{Authors' affiliations}

J P Pell, Department of Public Health, Greater Glasgow NHS Board, Glasgow, UK

G C S Smith, Department of Obstetrics and Gynaecology, University of Cambridge, UK

A Dominiczak, S M Cobbe, Division of Cardiovascular and Medical Sciences, University of Glasgow, UK

R Dobbie, Information and Statistics Division, Common Services Agency, Edinburgh, UK

A D McMahon, I Ford, Robertson Centre for Biostatistics, University of Glasgow, UK

Correspondence to: Dr Jill P Pell, Department of Public Health, Greater Glasgow NHS Board, Dalian House, 350 St Vincents Street, Glasgow G3 8YU, UK; jill.pell@gghb.scot.nhs.uk

Accepted 31 March 2003

\section{REFERENCES}

1 Godfrey KM, Barker DJ. Fetal nutrition and adult disease. Am J Clin Nutr 2000;71 (5 suppl): 1344S-52S.

2 Barker DJP. Fetal and infant origins of adult disease. London: BM, 1992.

3 Smith GC, Pell JP, Walsh D. Pregnancy complications and maternal risk of ischaemic heart disease: a retrospective cohort study of 129,290 births. Lancet 2001;357:2002-6.

4 Smith GD, Hart C, Ferrell C, et al. Birth weight of offspring and mortality in the Renfrew and Paisley study: prospective observational study. BM 1997;315: 1 189-93.

5 WOSCOPS Investigators. Screening experience and baseline characteristics in the West of Scotland Coronary Prevention Study. The WOSCOPS Study Group. West of Scotland coronary prevention study. Am J Cardiol 1995;76:485-91.

\section{IMAGES IN CARDIOLOGY}

\section{Spontaneous pneumopericardium}

$A^{n}$ n 86 year old physician with a history of advanced ischaemic cardiomyopathy and inducible ventricular tachycardia requiring an implantable cardioverterdefibrillator (ICD) presented with orthostatic symptoms and hypotension felt to be secondary to dehydration. ICD interrogation revealed no recent events. An ECG showed atrioventricular sequential pacing. The chest radiograph was remarkable for lucency under the pericardium (arrows in left hand panel below) which appears to extend into the mediastinum. A computed tomographic (CT) scan revealed large anterior pneumopericardium (arrows in right hand panel) extending from the inferior apex to the aortic root. Multiple bullae were present adjacent to the mediastinal air collection. Emergency echocardiography showed no evidence of cardiac temponade. The patient's hypotension resolved with fluid administration. He was treated conservatively and a follow up chest $x$ ray three months later revealed complete resolution of the pneumopericardium.

A S Iskander E C Schick A B Levin Ayman_s_iskander@lahey.org
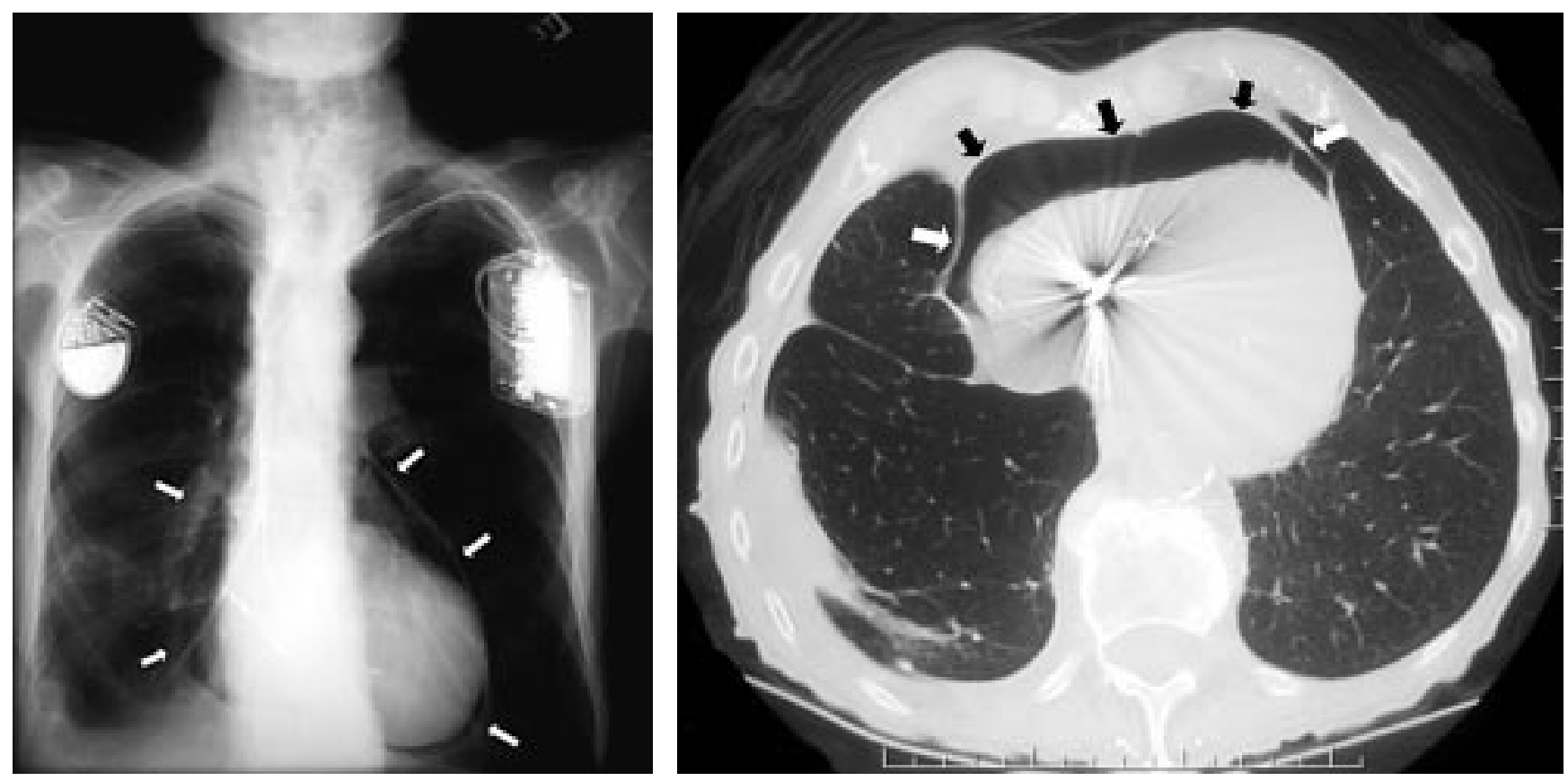